\title{
Technical note: Changes of cross- and auto-dependence structures in climate projections of daily precipitation and their sensitivity to outliers
}

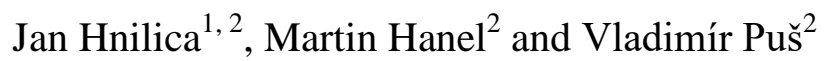 \\ ${ }^{1}$ Institute of Hydrodynamics of the Academy of Sciences of the Czech Republic, Pod Patankou 5, Prague 6, 166 12, Czech \\ Republic \\ ${ }^{2}$ Faculty of Environmental Sciences, Czech University of Life Sciences Prague, Kamýcká 129, Prague 6 - Suchdol, 165 21, \\ Czech Republic
}

Correspondence to: Jan Hnilica (hnilica@ih.cas.cz)

Abstract. Simulations of regional or global climate models are often used for climate change impact assessment. To eliminate systematic errors, which are inherent to all climate model simulations, a number of post processing (statistical downscaling) methods have been proposed recently. In addition to basic statistical properties of simulated variables, some of these methods consider also the biases and/or changes in dependence structure between variables or within. In the present paper we assess the biases and changes in cross- and auto-correlation structures of daily precipitation in six regional climate model simulations. In addition the effect of outliers is explored making distinction between ordinary outliers (i.e. values exceptionally small or large) and dependence outliers (values deviating from dependence structures). It is demonstrated that correlation estimates can be strongly influenced by few outliers even in large data sets. In turn, any statistical downscaling method relying on sample correlation/covariance can therefore provide misleading results. An exploratory procedure is proposed to detect the dependence outliers in multi-variate data and to quantify their impact on correlation structures.

\section{Introduction}

The investigation of climate change impact on hydrological cycle is one of the crucial topics in the field of water resources management and planning (Mehrotra and Saharma, 2015). Simulations of regional and global climate models (RCMs and GCMs) represent a fundamental data source for climate change impact studies. It is well known that raw climate model outputs cannot be used directly in impact studies due to inherent biases which are found even for basic statistical properties (Chen et al., 2015). The bias is caused primarily by simplified representation of important physical processes (Solomon et al., 2007), which is often resulting from low spatial resolution of the RCMs.

Therefore, many methods have been developed to post-process the climate model outputs in order to move their statistical indicators closer to observations. The overview of these methods is presented e.g. by Maraun et al. (2010). Precipitation is a key input into the hydrological climate change impact studies and at the same time it belongs to meteorological variables that are most affected by bias. The comparison of correction methods commonly used for precipitation data is provided by Teutschbein and Seibert (2012). Nevertheless, these standard methods correct only the bias in statistical indicators (mean, 
Hydrol. Earth Syst. Sci. Discuss., https://doi.org/10.5194/hess-2018-7

Manuscript under review for journal Hydrol. Earth Syst. Sci.

Discussion started: 19 February 2018

(c) Author(s) 2018. CC BY 4.0 License.

(c) (i)
Hydrology and

Earth System

Sciences

Discussions

variance, distribution function) of individual variables. The bias in persistence parameters of time series as well as the bias in cross-dependence structures between variables is often neglected. However, the dependence structures of the meteorological variables affect the hydrological response of a catchment (Bárdossy and Pegram, 2012; Ehret et al., 2012), thus their inadequate representation in the data can impair hydrological impact studies (Teng et al., 2015; Hanel et al., 2017).

In recent years several studies attempted to overcome this limitation. Hoffmann and Rath (2012) and Piani and Haerter (2012) focused on the relationship between precipitation and temperature data from single location. Bárdossy and Pegram (2012) developed two procedures correcting a spatial correlation structure of RCM precipitation. Mao et al. (2015) proposed stochastic multivariate procedure based on copulas. Johnson and Sharma (2012) developed procedure correcting common statistics (mean, variance) together with lag-1 autocorrelation in multiple-time scales. The procedure was later extended with recursive approach by Mehrotra and Sharma (2015) and subsequently with non-parametric quantile mapping by Mehrotra and Sharma (2016) to correct the bias in auto- and cross-dependence structures across multiple time scales. Different approach based on the principal components was presented by Hnilica et al. (2017), correcting bias in cross-covariance and cross-correlation structures.

This paper evaluates the biases and temporal changes in cross-and auto-correlation structures in multivariate precipitation data simulated by climate model. We further investigate whether the magnitude of the changes exceeds considerably the natural variability. The attention is finally paid to the effect of outlying values, which can significantly affect the correlations and can thus lead to artefacts in bias-corrected time series.

The paper is organised as follows. In Sect. 2 the data used in this study are presented and Sect. 3 describes the methodology. In Sect. 4 the results are reported and their consequences for climate changes impact studies are discussed. Section 5 closes the paper with a brief summary. 
Hydrol. Earth Syst. Sci. Discuss., https://doi.org/10.5194/hess-2018-7

Manuscript under review for journal Hydrol. Earth Syst. Sci.

Discussion started: 19 February 2018

(c) Author(s) 2018. CC BY 4.0 License.

(c) (1)

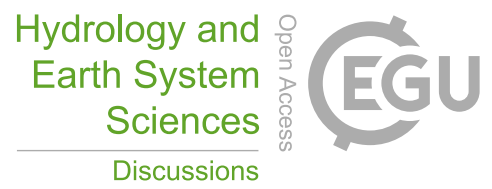

\section{Study area and data}

The cross- and auto- correlation structures of observed and RCM simulated daily precipitation for 13 river basins in the Czech Republic were analysed (see Fig. 1 and Table 1 for the location and details of the basins).

Table 1. Considered river basins.

\begin{tabular}{lll}
\hline Stream & Basin area $\left[\mathbf{k m}^{2}\right]$ & Basin ID \\
\hline Mze & 185.0 & 1 \\
Sedlistsky & 84.4 & 2 \\
Tepla & 93.4 & 3 \\
Liboc & 13.5 & 4 \\
Uhlavka & 276.9 & 5 \\
Tremosna & 47.6 & 6 \\
Utersky & 173.7 & 7 \\
Javornice & 86.1 & 8 \\
Strela & 629.4 & 9 \\
Libava & 45.2 & 10 \\
Rolava & 20.1 & 11 \\
Liboc & 49.8 & 12 \\
Podvinecky & 84.1 & 13 \\
\hline
\end{tabular}

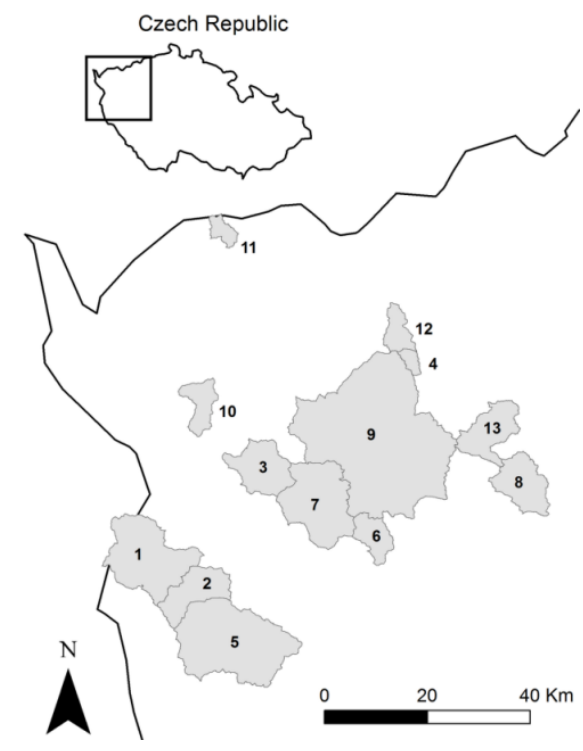

Figure 1. Location of the considered river basins in the Czech Republic. The numbers correspond to the basin ID from Table 1. 
Hydrol. Earth Syst. Sci. Discuss., https://doi.org/10.5194/hess-2018-7

Manuscript under review for journal Hydrol. Earth Syst. Sci.

Discussion started: 19 February 2018

(c) Author(s) 2018. CC BY 4.0 License.

(c) (i)
Hydrology and

Earth System

Sciences

Discussions

60 The observed time series of daily precipitation were derived from the gridded data-set provided by the Czech Hydrometeorological Institute (Štěpánek et al., 2011) at $25 \mathrm{~km} \times 25 \mathrm{~km}$ resolution as a weighted average of grid boxes intersecting the basin with weights proportional to the intersection area.

Simulations of two EURO-CORDEX (Giorgi et al., 2009) RCMs (with 0.11 degree resolution) driven by three GCMs forced by RCP8.5 were considered (see Table 2 for the overview of simulations). The control period spans the years from 1971 to

652000 , the future period the years from 2051 to 2080. The simulated data have been interpolated to the catchment area in the same way as the observed data.

Table 2. Global and regional climate models used in the present study.

\begin{tabular}{lll}
\hline GCM & RCM & ID \\
\hline EC-EARTH & CCLM-4-8-17 & 1A \\
& RCA4 & 1B \\
HadGEM2-ES & CCLM-4-8-17 & 2A \\
& RCA4 & 2B \\
MPI-ESM-LR & CCLM-4-8-17 & 3A \\
& RCA4 & 3B \\
\hline
\end{tabular}

\section{Methods}

70 The sample correlation coefficient $r_{X, Y}$ between random samples $X=\left(x_{1}, \ldots, x_{n}\right)$ and $Y=\left(y_{1}, \ldots, y_{n}\right)$ was calculated according to

$r_{X, Y}=c_{X, Y} / s_{X} s_{Y}$

where $c_{X, Y}$ denotes the sample covariance in the form

$c_{X, Y}=\frac{1}{n-1} \sum_{i=1}^{n}\left(x_{i}-\bar{x}\right)\left(y_{i}-\bar{y}\right)$

75 and $s_{X}$ denotes the sample standard deviation in the form

$s_{X}=\sqrt{\frac{1}{n-1} \sum_{i=1}^{n}\left(x_{i}-\bar{x}\right)^{2}}$

The symbol $\bar{x}$ denotes the sample (arithmetic) mean and $n$ denotes the sample size. 
Hydrol. Earth Syst. Sci. Discuss., https://doi.org/10.5194/hess-2018-7

Manuscript under review for journal Hydrol. Earth Syst. Sci.

Discussion started: 19 February 2018

(c) Author(s) 2018. CC BY 4.0 License.

(c) (i)
Hydrology and

Earth System

Sciences

Discussions

Data from individual basins were arranged to a 13 -dimensional random vector $\boldsymbol{X}=\left(X_{1}, \ldots, X_{13}\right)$, where subscripts $1, \ldots, 13$ denote the basin ID from Table 1. The sample correlation between the variables $X_{i}$ and $X_{j}$ is denoted as $r_{i, j}$ The symbol $\mathbf{R}$ denotes the correlation matrix (i.e. the square matrix with elements $r_{i, j}$ ). The auto-correlation structures were analysed through the auto-correlation function of the time series from individual basins. The lag- $k$ auto-correlation from basin $i$ (the basin with ID $i$ ) is denoted as $r_{i}^{k}$.

The model biases and changes were investigated. In general, a change of an indicator (correlation, auto-correlation) $\alpha$ between control period $\mathrm{C}$ and future period $\mathrm{F}$ was calculated as

$\Delta \alpha=\alpha_{\mathrm{F}}-\alpha_{\mathrm{C}}$

where $\Delta \alpha$ denotes the change of $\alpha$, subscripts denote the period. The symbol $\Delta r_{i, j}$ thus denotes the change of the corresponding cross-correlation; the symbol $\Delta r_{i}^{k}$ denotes the change of the corresponding auto-correlation. If appropriate, the subscripts denoting the basin are omitted for clarity. The model bias is obtained in the similar way, replacing $\alpha_{\mathrm{C}}$ by the observed and $\alpha_{\mathrm{F}}$ by the simulated (from the control period) values of $\alpha$ in Eq. (4).

The sampling variability of individual cross- and auto-correlation was investigated to assess the statistical significance of their changes. The confidence intervals were derived using the block bootstrap approach (Davison and Hinkley, 1997). Specifically, the confidence interval around the correlation $r_{i, j}$ was obtained as follows:

1. one-year blocks from the time series for basins $i$ and $j$ were randomly selected with replacement (30-times to obtain the same sample size as the original data), subsequently the correlation of the 30 -year sample was calculated

2. step 1 was repeated 1000 times

3. the $95 \%$ confidence interval was derived as a range between the 0.025 and 0.975 quantiles of the resampled correlations.

The block approach was chosen to preserve a seasonal variability in the bootstrap samples. For the presentation of confidence intervals, the unique identifier (ID) was assigned to each pair of basins, the numbering was done according to rows of correlation matrix; the scheme is depicted in Fig. 2. The confidence intervals for auto-correlation were derived in the same way using one-year blocks of time series. The joints of the adjacent blocks were not included in the calculation. 
Hydrol. Earth Syst. Sci. Discuss., https://doi.org/10.5194/hess-2018-7

Manuscript under review for journal Hydrol. Earth Syst. Sci.

Discussion started: 19 February 2018

(c) Author(s) 2018. CC BY 4.0 License.

\section{(c) (1)}

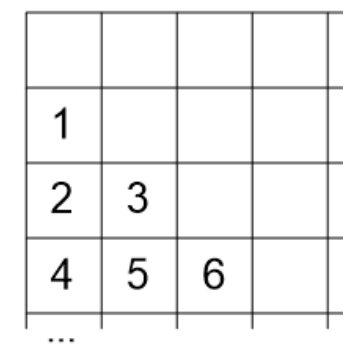

Hydrology and

Earth System

Sciences

Discussions

Figure 2. Numbering of individual pairs of basins. The figure depicts the upper left corner of the correlation matrix with rows/columns ordered as in Table 1; the numbers represent identifiers used in Fig. 4.

\section{Results and discussion}

\subsection{Bias in correlation structures}

Prior to the examination of changes, the model simulations from the control period were compared to observations. The model biases were calculated in accordance with Eq. (4). In the case of 13-dimensional data, the bias of the cross-correlation structure consists of biases in $r_{i, j}$ coefficients for 78 pairs of basins (corresponding to the sub-diagonal part of the correlation matrix). For clarity, these 78 biases are presented in the form of box-plots for individual models.

(a)

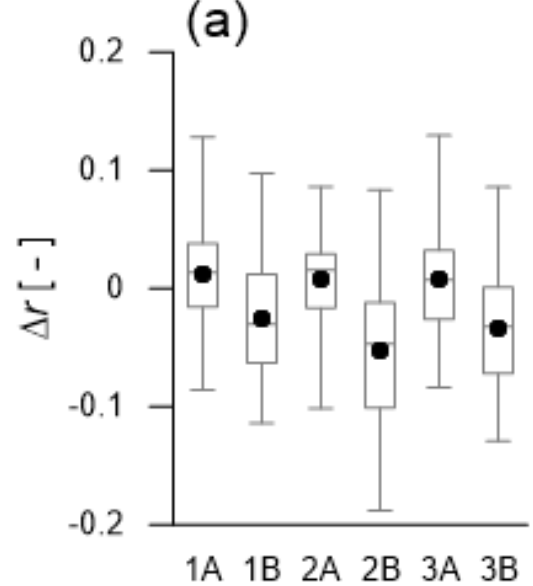

(b)

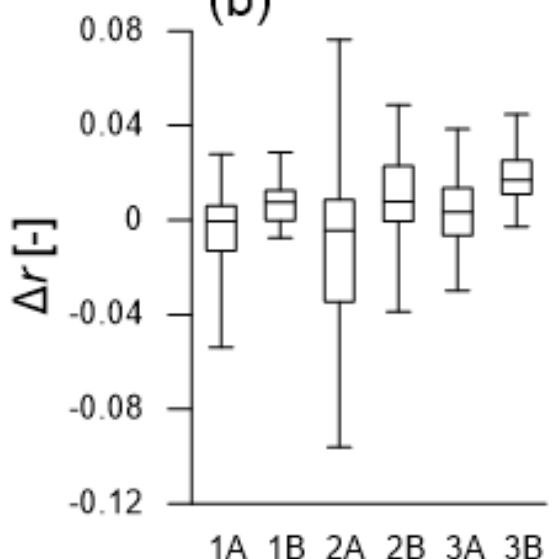

(c)

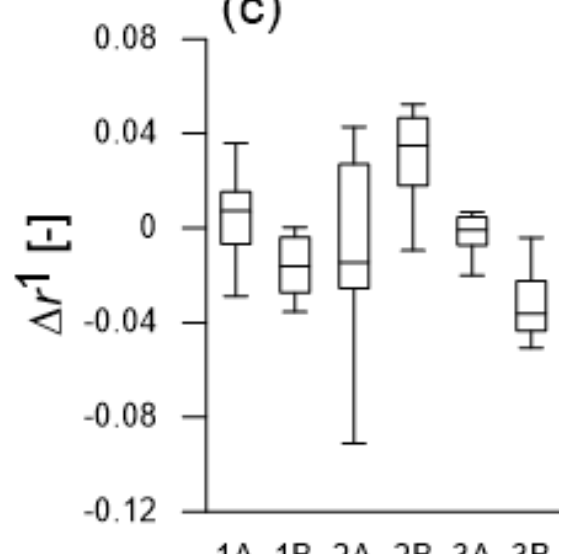

Figure 3. Overview of the biases and changes of correlation structures for all models: (a) the bias of cross-correlation, the black dots represent the means of datasets, (b) the change of cross-correlation, (c) the change of auto-correlation.

The box-plots representing bias in the cross-correlation are given in Fig. 3a, the black dots in box-plots represent the mean values. The location of mean values for each model clearly indicates that the overall bias is determined by the regional model, in general the CCLM-4-8-17 overestimates and RCA4 underestimates the correlations. This finding points to the different scales of global and regional models. The global climate model generates a large-scale signal which is transformed 
Hydrol. Earth Syst. Sci. Discuss., https://doi.org/10.5194/hess-2018-7

Manuscript under review for journal Hydrol. Earth Syst. Sci.

Discussion started: 19 February 2018

(c) Author(s) 2018. CC BY 4.0 License.

(c) (i)
Hydrology and

Earth System

Sciences

Discussions

by regional climate model into a more detailed and spatially distributed information (Bader et al., 2008). The correlation coefficient is an index expressing solely the intensity of linear relationship between two variables (locations). Therefore, it is given primarily by the regional model. Figure 3a shows that while the model A (CCLM-4-8-17) mostly overestimates the correlation, the model B (RCA4) mostly underestimates them and shows higher magnitude of bias.

In contrast to cross-correlation structures, the bias in auto-correlation structures is model independent and do not contain obvious patterns as the results presented in Fig. 3a. In general, the auto-correlation is mostly underestimated; the biases of $r^{1}$ fluctuate in a range from -0.1 to 0.04 .

\subsection{Changes in correlation structures}

The changes between the control and future period were calculated using Eq. (4). The results are presented in the form of box-plots for individual models, analogously to the previous section. Figures $3 \mathrm{~b}$ and $3 \mathrm{c}$ present the changes of crosscorrelation and auto-correlation structures, respectively. The figures show that the changes range from -0.1 to 0.08 ; the highest changes are reached by the model $2 \mathrm{~A}$. In relative expression, the maximal changes of cross-correlation reach up to $12 \%$ of the value from the control period, in the case of auto-correlation it is almost $30 \%$, as the auto-correlations are in general markedly lower than cross-correlations (the mean cross-correlation of individual models exceeded 0.8 , the mean lag1 auto-correlation is around 0.23 ).

We further assessed the significance of the changes using a block bootstrap. The results for the models $2 \mathrm{~A}$ and $3 \mathrm{~B}$ are presented, since the model $2 \mathrm{~A}$ reached the highest changes and the model $3 \mathrm{~B}$ reached the highest portion of significant changes. Figure 4 presents the $95 \%$ confidence intervals of individual cross-correlations. The model $2 \mathrm{~A}$ demonstrates only a little significance - in most cases the intervals from the control and future periods substantially overlap. In the case of model 3B approximately a quarter of changes can be considered significant - the intervals overlap slightly or do not overlap at all. 
Hydrol. Earth Syst. Sci. Discuss., https://doi.org/10.5194/hess-2018-7

Manuscript under review for journal Hydrol. Earth Syst. Sci.

Discussion started: 19 February 2018

(c) Author(s) 2018. CC BY 4.0 License.
Hydrology and

Earth System

Sciences

Discussions

(c) (i)

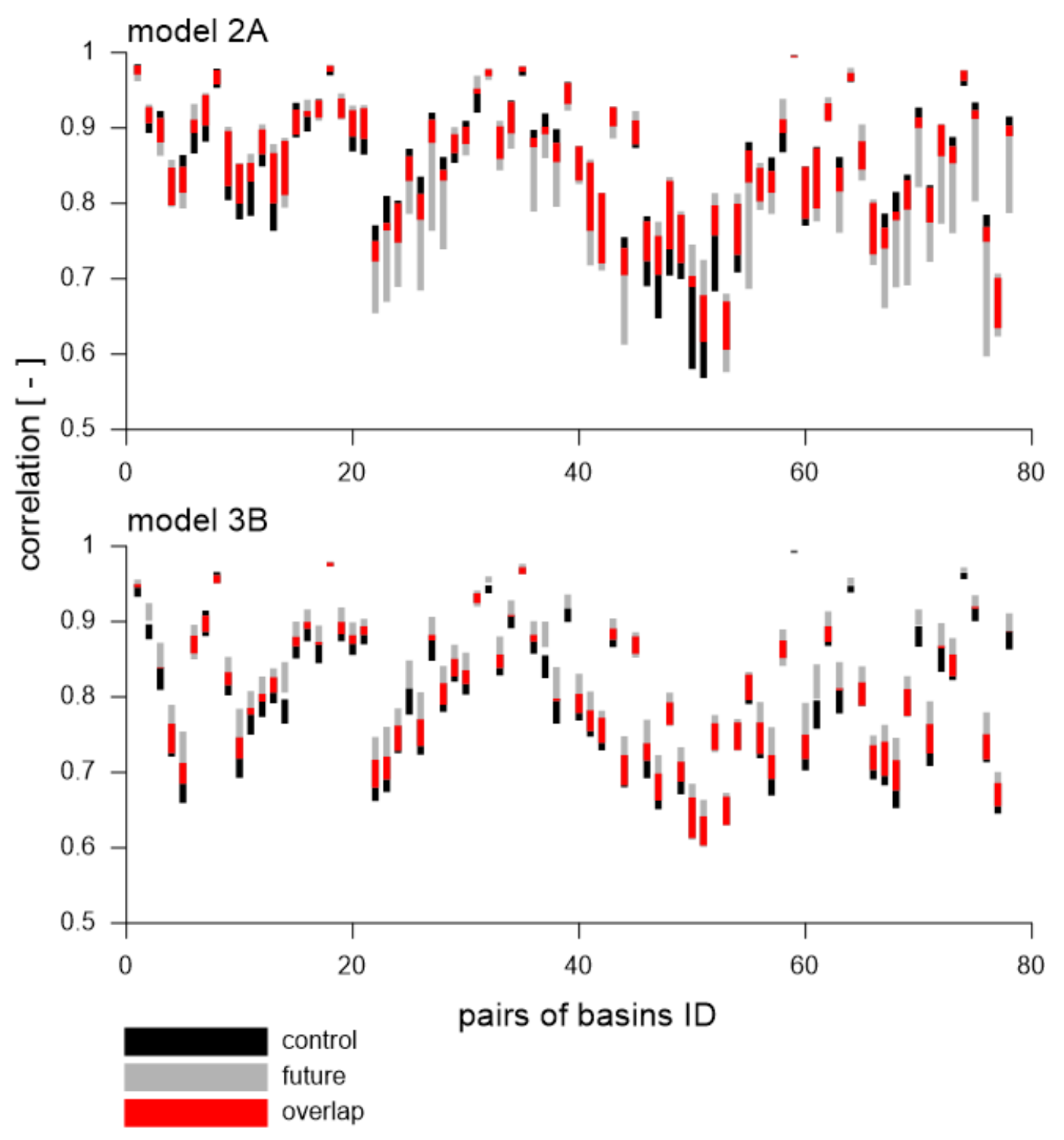

Figure 4. The $95 \%$ confidence intervals of the cross-correlation for the models $2 \mathrm{~A}$ and $3 \mathrm{~B}$. The identifiers (ID) of individual pairs of basins are explained in Fig. 2.

Figure 5 presents the same for the lag-1 auto-correlations of individual basins and the overall information is similar to those provided by Fig. 4 . The changes simulated by other models (in the case of cross- and auto-correlations) do not exceed the sampling variability in most cases and in general they are less significant than the changes of the model 3B (not shown). 
Hydrol. Earth Syst. Sci. Discuss., https://doi.org/10.5194/hess-2018-7

Manuscript under review for journal Hydrol. Earth Syst. Sci.

Discussion started: 19 February 2018

(C) Author(s) 2018. CC BY 4.0 License.
Hydrology and

Earth System

Sciences

Discussions

(c) $\underset{\mathrm{BY}}{\mathrm{P}}$

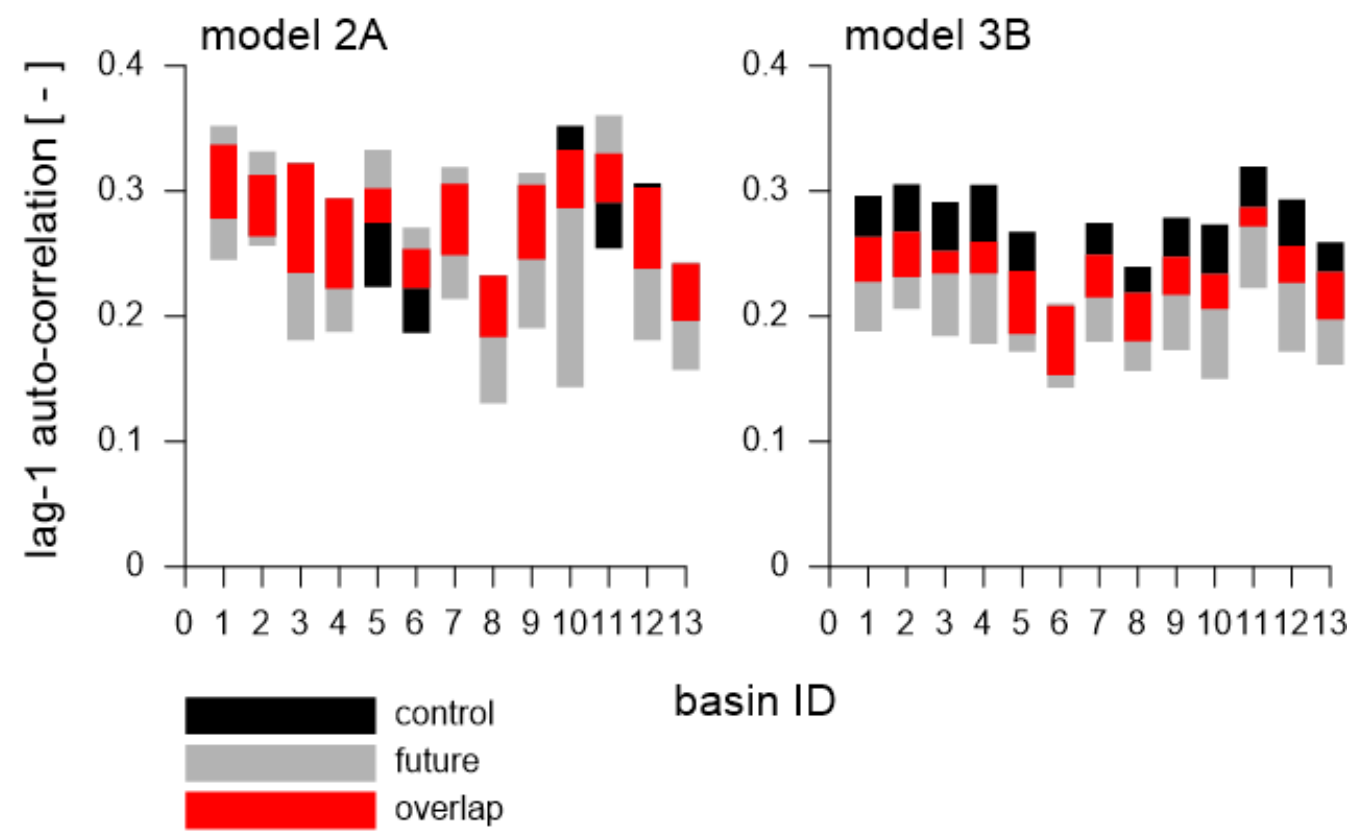

Figure 5. The $95 \%$ confidence intervals of the lag-1 auto-correlation for the models $2 \mathrm{~A}$ and $3 \mathrm{~B}$.

\subsection{Effect of outliers}

The previous section demonstrated that the changes in dependence according to model $2 \mathrm{~A}$ mostly show a little significance despite of their high absolute values. Nevertheless, Figs. 4 and 5 demonstrate that the confidence intervals for the model 2A are exceptionally wide in many cases. Further analyses showed that this instability of correlation estimates is introduced by outlying values, which causes seeming changes of the correlation structures.

In the simulation of the model $2 \mathrm{~A}, r_{6,8}$ decreased from 0.9 in the control period to 0.84 in the future period. Figure $6 \mathrm{a}$ depicts the data from the future period (values from the basin 6 plotted against values from the basin 8 ). The decrease is entirely caused by two outliers, which are both circled by solid lines in the plot. Their removal from the data increases the correlation in the future period to 0.9 , which reduces the change almost to zero. We note that the third noticeable outlier (circled by dashed line) does not affect the correlation, since the location of the point is in accordance with the configuration of data the point lies approximately in a direction of a potential regression line. 
Hydrol. Earth Syst. Sci. Discuss., https://doi.org/10.5194/hess-2018-7

Manuscript under review for journal Hydrol. Earth Syst. Sci.

Discussion started: 19 February 2018
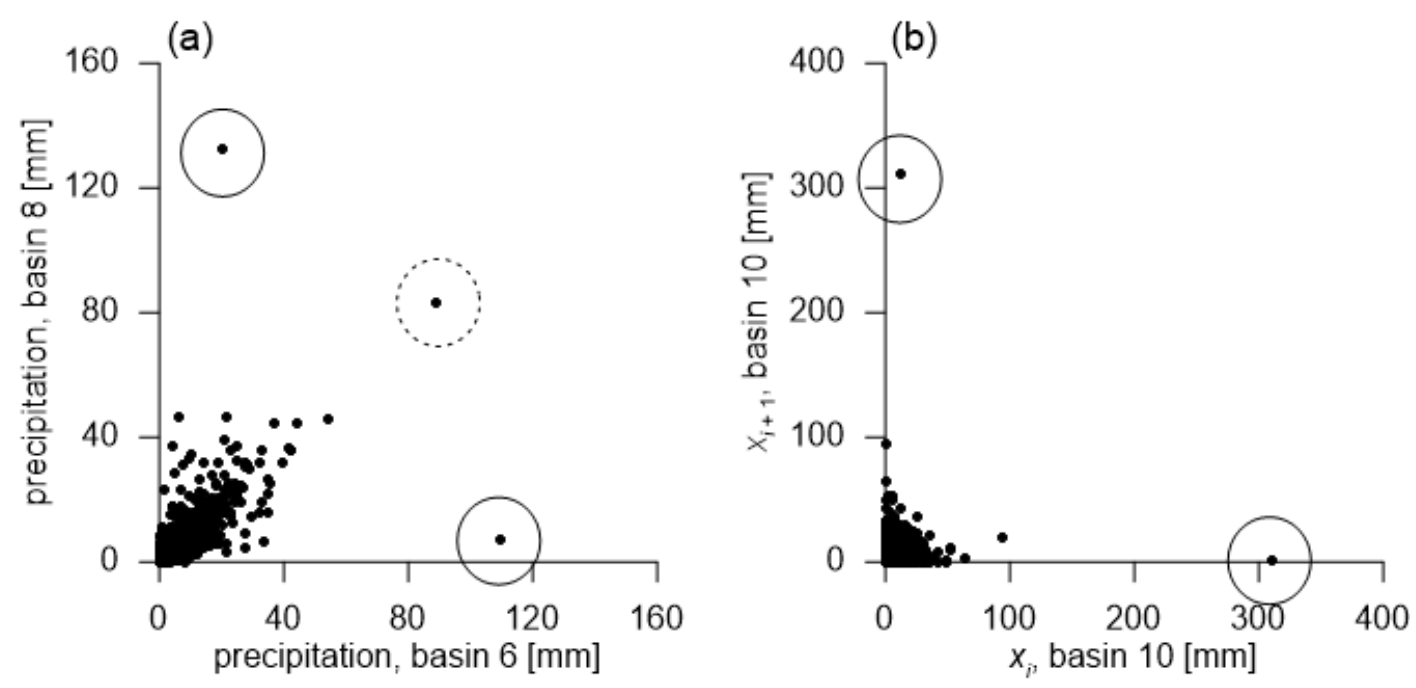

Figure 6. The effect of outlier on correlation structures of model 2A in the future period: (a) data from the basins 6 and 8 , the outliers are circled by solid lines (the outlier circled by dashed line does not affect the correlation structure), (b) the calculation of $r^{1}$ in the basin 10 the values $x_{i}$ plotted against the values $x_{i+1}$, where $i$ denotes the order of value $x$ in the time series, outlier $310.1 \mathrm{~mm}$ is circled.

The largest change of the auto-correlation was achieved by the model $2 \mathrm{~A}$ for the basin 10 , where $r_{10}^{1}$ decreased from 0.32 in the control period to 0.22 in the future period. This decrease in caused by outlier $310.1 \mathrm{~mm}$ in the future data; this extraordinary value was simulated by the model $2 \mathrm{~A}$ for the $8^{\text {th }}$ May 2080. Figure $6 \mathrm{~b}$ depicts the data for the calculation of $r_{10}^{1}$, i.e. the values $x_{i}$ plotted against the values $x_{i+1}$, where $i$ denotes the order of the value $x$ in the time series. The outlier $310.1 \mathrm{~mm}$ is employed twice within the calculation (as $x_{i}$ and as $x_{i+1}$, circled values in Fig. 6b) which markedly affects the result. If the outlier is removed from the time series, $r_{10}^{1}$ increases from 0.22 to 0.31 , which dramatically reduces the change. The calculation of other members of the auto-correlation function is affected by the outlier in the same way. We note, that the effect of an outlier to the auto-correlation strongly depends on values, by which the outlier is surrounded in the time series. The presence of noticeable outlier thus makes the calculation of the auto-correlation very unstable. It is worth noting, that the estimates of the bias in the climate model simulated dependence characteristics can be affected by outliers in the same way.

\subsection{Detection of outliers}

The examples showed that several outliers can distort cross- and auto-correlation structures of a large dataset comprising many thousands values. Nevertheless; it should be taken into consideration that an extreme value does not necessarily affect the correlation (as seen in Fig. 6a). Therefore a more specific concept of outliers is presented in this study. Values deviating from the correlation structure are denoted as dependence outliers. As well as ordinary outliers, the dependence outliers are values at a long distance from the origin; nevertheless, the difference between them and ordinary outliers consists in a 
Hydrol. Earth Syst. Sci. Discuss., https://doi.org/10.5194/hess-2018-7

Manuscript under review for journal Hydrol. Earth Syst. Sci.

Discussion started: 19 February 2018

(c) Author(s) 2018. CC BY 4.0 License.

(c) (i)
Hydrology and

Earth System

Sciences

Discussions

coordinate system in which the distance is measured. Figure 7 illustrates this by an example of synthetic 2-dimensional data. The dashed lines and coordinates in square brackets define the standard (canonical) coordinate system. The ordinary outliers are points in a long distance from the origin [0,0], measured in the standard coordinates; the point A represents an example. The solid lines and coordinates in round brackets define an alternative coordinate system, which reflects the intensity of linear dependence between the variables $\mathrm{X}$ and $\mathrm{Y}$. The dependence outliers are points in a long distance from the origin $(0$, 0 ), measured in the alternative coordinates; the point B represents an example. Let us remark that the point B does not represent an extreme value neither in $\mathrm{X}$ nor $\mathrm{Y}$ data, in contrast to the point $\mathrm{A}$. Nevertheless, the point B deviates from the dependence structure, which comes out when its distance from $(0,0)$ in alternative coordinates is calculated. The alternative coordinate system is constructed through the covariance matrix of the data. The directions of the axes are given by the eigenvectors of the matrix, the lengths of unit vectors are given by the square root of the corresponding eigenvalues and the origin is located in the mean of the data. The construction of the system is related to the principal component analysis; see for example Wilks (2011) for details.

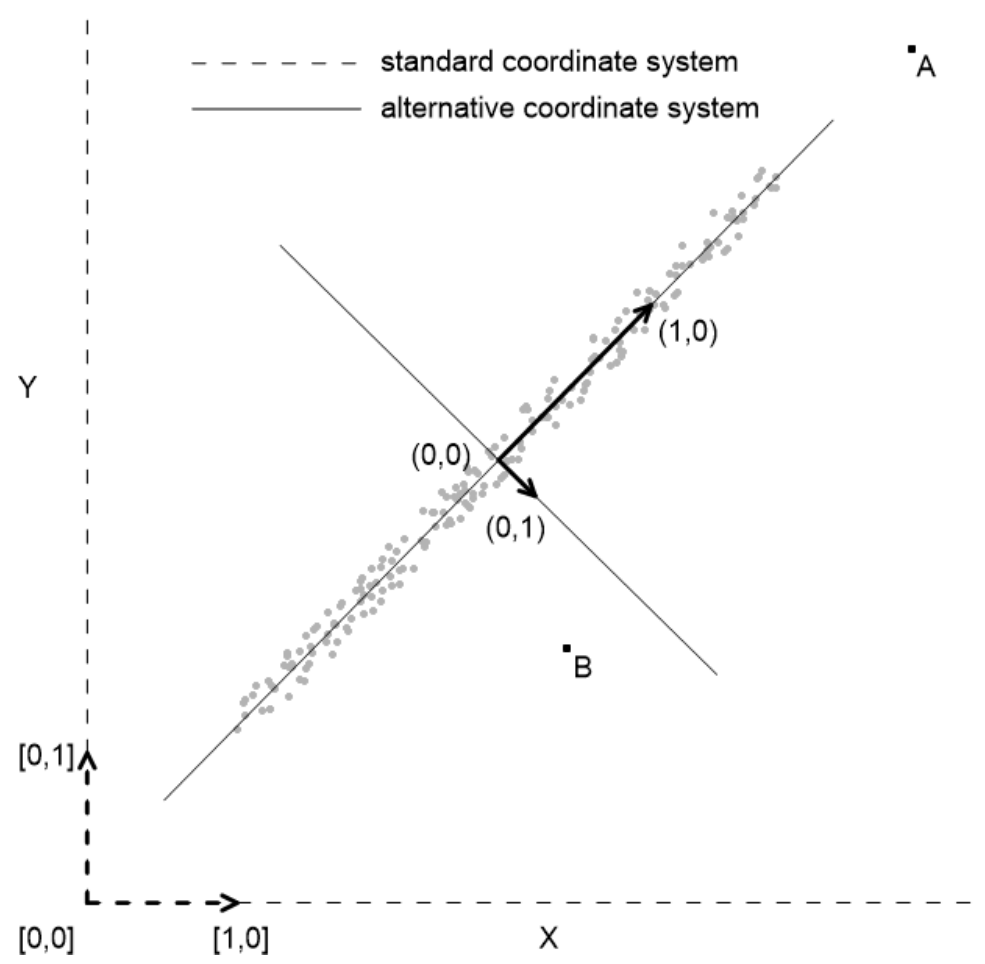

Figure 7. The differences between the ordinary outliers and the dependence outliers. The dashed lines define the standard coordinate system; the solid lines define an alternative coordinate system. The points outlying in the standard coordinates are ordinary outliers (point A); the points outlying in the alternative coordinates are denoted as dependence outliers (point deviating from the dependence structure, point B). The construction of alternative coordinates is explained in the text. 
Hydrol. Earth Syst. Sci. Discuss., https://doi.org/10.5194/hess-2018-7

Manuscript under review for journal Hydrol. Earth Syst. Sci.

Discussion started: 19 February 2018

(c) Author(s) 2018. CC BY 4.0 License.

(c) (i)
Hydrology and

Earth System

Sciences

Discussions

195 The problem is that the presence of outliers is not simply detectable from the changes of dependence structures. It can be either indicated indirectly from the analysis of sampling variability; nevertheless the wide confidence intervals do not necessarily imply the presence of outliers. Alternatively, it can be found out when the individual pairs of datasets are visually checked. Therefore we propose a procedure allowing for identification of significant dependence outliers and assessment of their effect on correlation structure. The procedure consists of three steps:

1. the most outlying (multi-variate) value is found in the data

2. the value is removed from the data and a new correlation matrix is calculated

3. a difference between the new and the previous correlation matrix is calculated and recorded.

These three steps are repeated. The difference in step 3 is quantified through

$$
\delta \mathbf{R}_{m}=\left\|\mathbf{R}_{m}-\mathbf{R}_{m-1}\right\|
$$

where $\mathbf{R}_{m}$ denotes the correlation matrix of the data from which $m$ largest outliers were removed, the symbol $\|\cdot\|$ denotes the Frobenius matrix norm. The most outlying value in the step 1 is simply defined as the value with the highest distance from origin (measured in the alternative coordinates). A result of the proposed exploratory procedure is a sequence of $\delta \mathbf{R}_{m}$, which clearly indicates the presence of noticeable outliers.

The procedure is demonstrated using the data from Fig. 6a, i.e. 2-dimensional data from basins 6 and 8 (model 2A). Figure 8 depicts $\delta \mathbf{R}_{m}$ for the future data (black bars) and for the control data (red bars). A massive impact of the first two outliers in future data is clearly visible; the removal of next outliers already does not affect the correlation matrix substantially (the first two members $\delta \mathbf{R}_{1}$ and $\delta \mathbf{R}_{2}$ correspond to the circled outliers in Fig. 6a). In the case of control data, a gradual evolution of $\delta \mathbf{R}_{m}$ indicates that the data do not contain noticeable outliers. 
Hydrol. Earth Syst. Sci. Discuss., https://doi.org/10.5194/hess-2018-7

Manuscript under review for journal Hydrol. Earth Syst. Sci.

Discussion started: 19 February 2018

(c) Author(s) 2018. CC BY 4.0 License.

(c) (i)

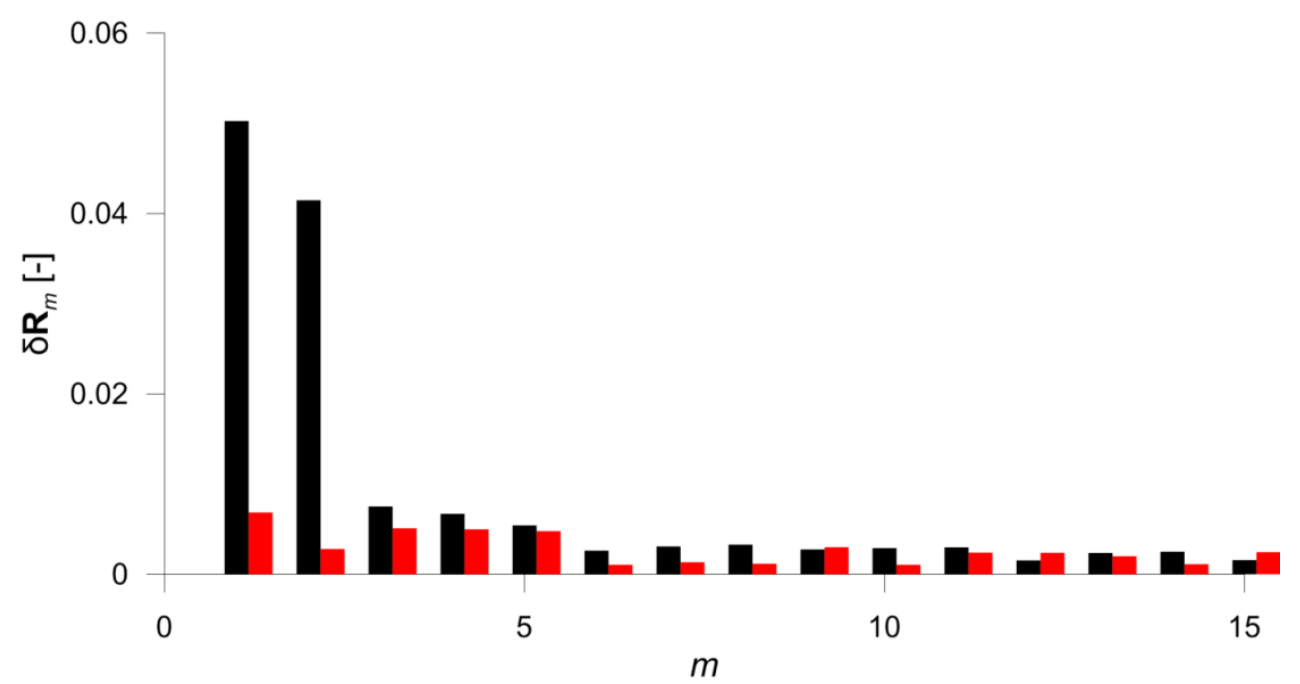

215 Figure 8. The detection of dependence outliers for 2-dimensional data from basins 6 and 8, model $2 \mathrm{~A}$ : the evolution of $\delta \mathrm{R}_{m}$ for the future period (black bars), the evolution of $\delta \mathrm{R}_{m}$ for the control period (red bars). The plot indicates two noticeable outliers in the future data (compare with Fig. 6a).

We note that the alternative coordinate system in which the dependence outliers are searched is data-dependent (in contrast to the standard coordinates). It means that after each removal of outlier the alternative coordinates slightly change and must be recalculated to correspond to the actual data. Generally, a plot of $\delta \mathbf{R}_{m}$ enables a simple assessment of the internal structure of the data and a direct evaluation of an importance of individual outliers.

Interesting results are obtained, when the evolution of $\delta \mathbf{R}_{m}$ is calculated for complete 13-dimensional data of the model $2 \mathrm{~A}$. Figure 9a depicts $\delta \mathbf{R}_{m}$ for the control period, Fig. $9 \mathrm{~b}$ depicts the same for the future period. The correlation structures are in both cases substantially affected mainly by the first approximately 50 outliers. 
Hydrol. Earth Syst. Sci. Discuss., https://doi.org/10.5194/hess-2018-7

Manuscript under review for journal Hydrol. Earth Syst. Sci.

Discussion started: 19 February 2018

(c) Author(s) 2018. CC BY 4.0 License.

(c) (i)

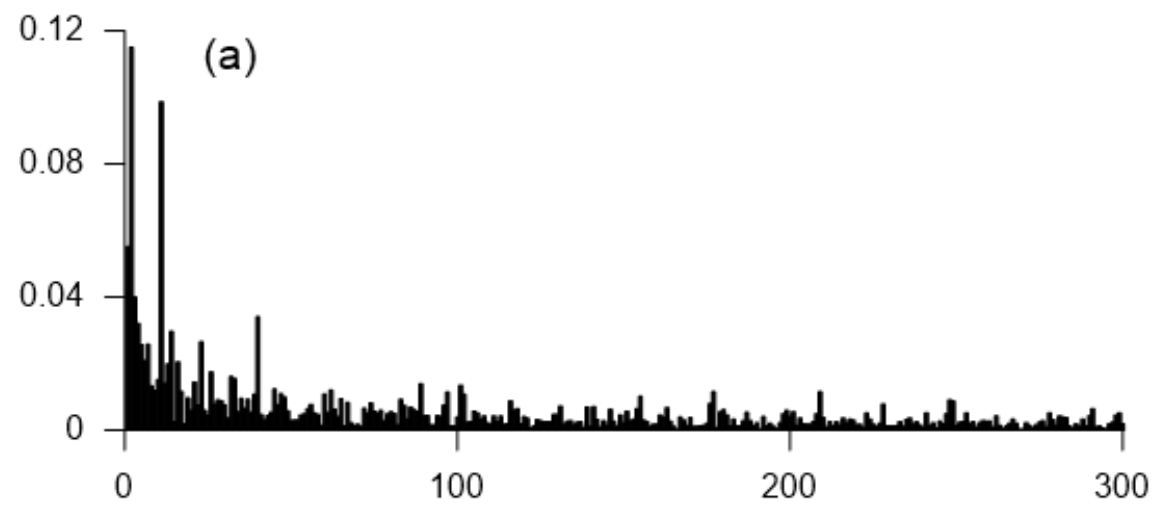

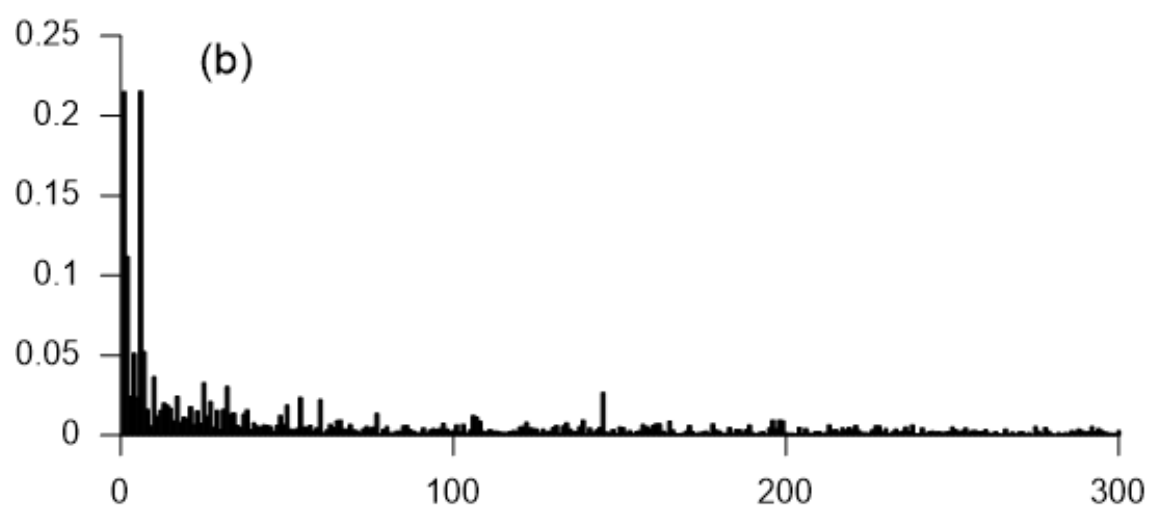

Figure 9. The detection of dependence outliers for complete 13-dimensional data, model $2 \mathrm{~A}$ : (a) the evolution of $\delta \mathrm{R}_{m}$ for the control period, (b) the evolution of $\delta \mathrm{R}_{m}$ for the future period. The correlation structures are in both cases affected mainly by the first approximately 50 outliers.

Based on this result, 50 outliers (corresponding to $\delta \mathbf{R}_{1} \ldots \delta \mathbf{R}_{50}$ ) were removed from the data from both periods and the changes in cross-correlation structures for the data without outliers were calculated. Figure 10 compares the changes for the complete data (white box-plot) and for the data without outliers (grey box-plot). As seen from the figure, the removal of outliers dramatically reduces temporal changes of correlation structure. Therefore, it can be considered that the data of model 2A are composed of two parts. The first one incorporates an absolute majority of the data and its correlation is stable in time. The second one includes a small part of the most outlying values (4.6 per mille in this example) and produces the main part of temporal changes of the correlation structure. The same procedure applied to other models showed, that a similar effect was markedly visible in the simulations of the regional model A; the results for model B were less convincing (not shown), as the outputs from the model B generally contain less outliers. 
Hydrol. Earth Syst. Sci. Discuss., https://doi.org/10.5194/hess-2018-7

Manuscript under review for journal Hydrol. Earth Syst. Sci.

Discussion started: 19 February 2018

(c) Author(s) 2018. CC BY 4.0 License.

(c) (i)

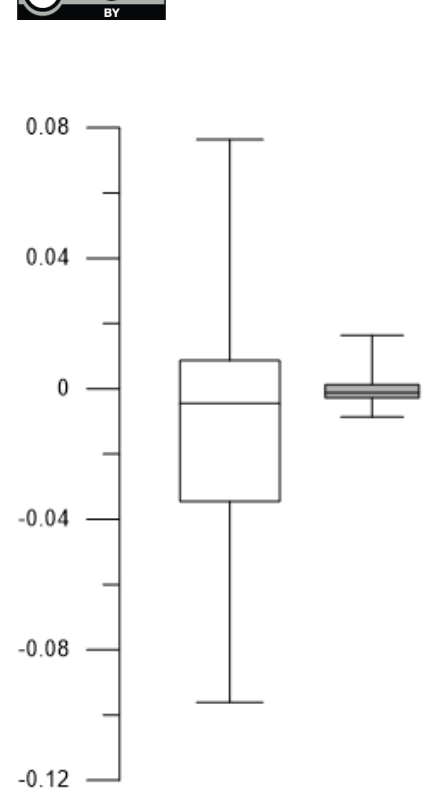

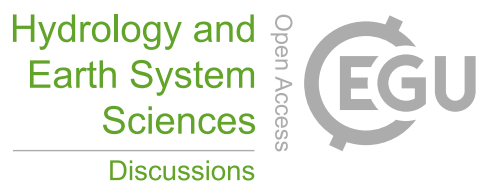

Discussions

Figure 10. The box-plots summarise the values of $\Delta r$ for the complete data (white box) and for the data without 50 dependence outliers

(grey box) for the model $2 \mathrm{~A}$. The dependence outliers removed from the data correspond to $\delta \mathrm{R}_{1} \ldots \delta \mathrm{R}_{50}$ from the Fig. 9 .

\subsection{Rank correlations}

The effect of outliers on correlation structures can be eliminated when the rank correlations are considered. Figure 11 depicts the bootstrap intervals for the models 2A and 3B, analogously as in Fig. 4; but in this case calculated through Spearman rank correlations. From the comparison of both figures it is obvious that the bootstrap intervals derived from rank correlations are thinner than the intervals around Pearson correlations, particularly in the case of model 2A. Rank correlation structures also show considerably higher number of significant changes. 
Hydrol. Earth Syst. Sci. Discuss., https://doi.org/10.5194/hess-2018-7

Manuscript under review for journal Hydrol. Earth Syst. Sci.

Discussion started: 19 February 2018

(c) Author(s) 2018. CC BY 4.0 License.

(c) (i)
Hydrology and

Earth System

Sciences

Discussions

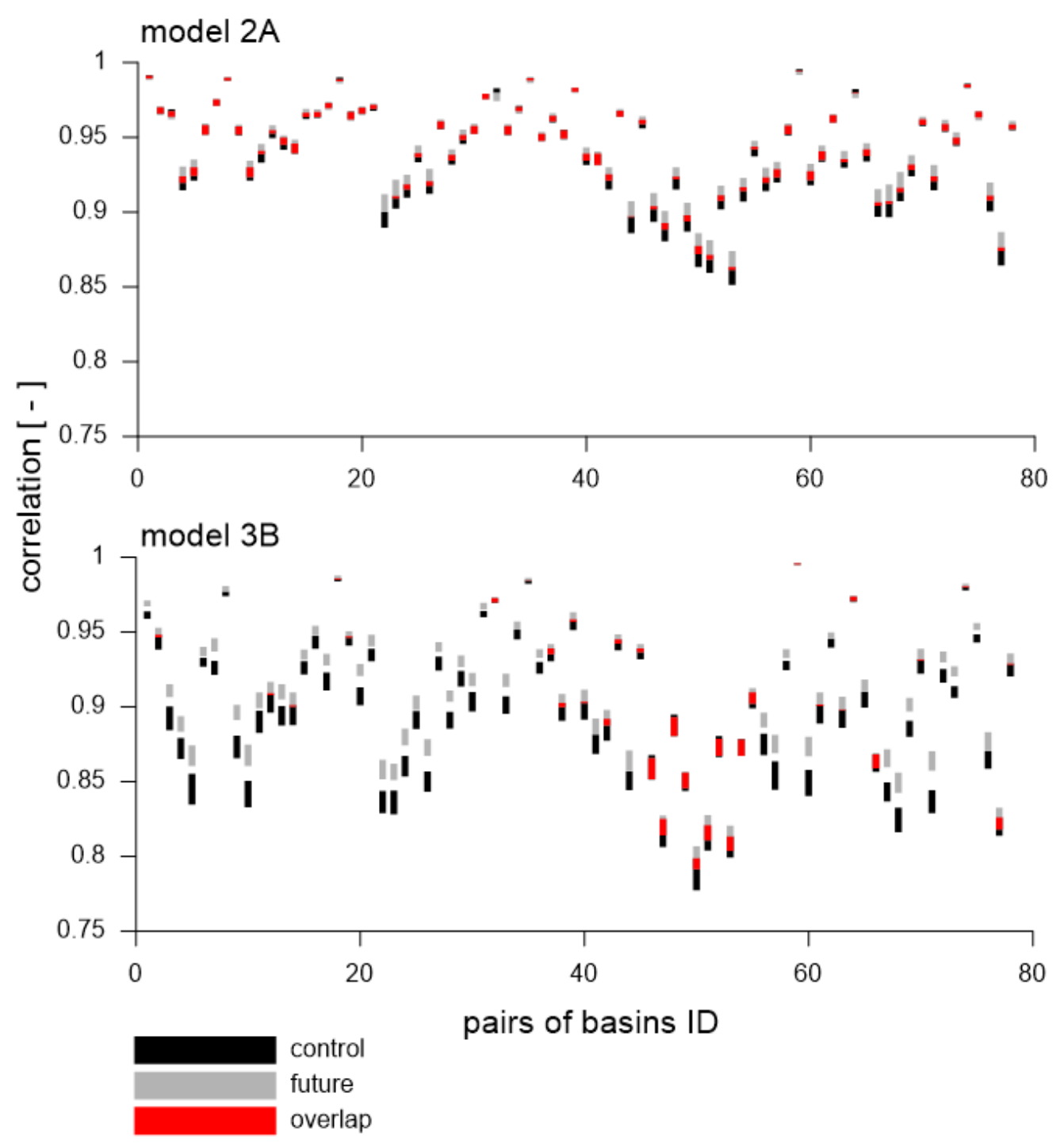

Figure 11. The $95 \%$ confidence intervals of the rank cross-correlation for the models $2 \mathrm{~A}$ and $3 \mathrm{~B}$. The identifiers (ID) of individual pairs of basins are the same as in Fig. 4 (and explained in Fig. 2).

Nevertheless, there are several questionable points concerning rank correlations of precipitation data. The precipitation data contain a high number of zero values which must be treated otherwise the rank correlation is distorted by severe artefacts. A possible way is to consider the correlations only for non-zero values, however this approach results into a loss of information and furthermore it is not applicable to auto-correlations. Therefore the joint (average) rank was assigned to each zero value in this study (we note that the results can differ if e.g. random rank is applied instead). Further, the information provided by both correlation coefficients differs; Spearman correlations systematically reach higher values. In addition, the difference between Pearson and Spearman rank correlation coefficients is related to the intensity of linear dependence: the differences 
Hydrol. Earth Syst. Sci. Discuss., https://doi.org/10.5194/hess-2018-7

Manuscript under review for journal Hydrol. Earth Syst. Sci.

Discussion started: 19 February 2018

are higher for lower intensities (for Pearson about 0.6 the Spearman is approximately about $40 \%$ higher). Finally, the rank correlations are designed to avoid the limitation to linear relation between variables considering a more general monotone relation instead. Nevertheless, the precipitation data often show a more or less tight linear dependence and from this point of view there is no need to leave the linear approach.

\subsection{Changes of covariance}

To complete the information about the temporal changes of dependence structures, the changes of covariance were analysed. The overall result is that the covariance structures change substantially more than correlations. The mean change of covariance reaches up to $50 \%$ of the values from the control period and it varies considerably among the models. The covariance is a mixed measure, including an intensity of linear dependence between variables and their variability. Thus a change of covariance is tightly related to a change of variability. A strong linear relation (with coefficient of determination 0.99) was found between the mean changes of standard deviations and the mean changes of covariance for individual models (not shown). The covariance structures are also highly sensitive to the outliers; nevertheless in this case the classical extreme values are considered, as they affect primarily the variances of the individual variables.

\subsection{Consequences for climate change impact studies}

The examples demonstrated that several outliers (or several per mille of the most outlying values) can strongly affect the cross- and auto-correlation structures of the data comprising many thousand values. In general, it must be stressed that the presence of outliers cannot be considered as a bias. The extreme precipitation values as well as the dependence outliers naturally occur. Nevertheless, although the dependence structures are markedly influenced by small number of outliers, they characterize the data as a whole. Therefore a substantial bias can arise when the data with noticeable outliers are used to assess the dependence structures or when their dependence structures are used e.g. for calibration the bias correction functions or weather generators, as in several recent studies. The cross- and auto-correlation structures are the key ingredients in multi time-scale bias correction presented by Mehrotra a Sharma (2015) and Mehrotra a Sharma (2016). Efstratiadis et al. (2014) use the Cholesky decomposition of cross-covariance matrix for generating the synthetic time series. Hnilica et al. (2017) use the principal components derived from the cross-covariance matrices for the bias correction of multivariate model data. The results based on the methods proposed in these studies can be devalued by outliers. The appropriate tool for testing the presence of outliers is the analysis $\delta \mathbf{R}_{m}$ presented above; the exploratory procedure can be automatized and included in the modelling chain as a pre-processing step to automatically remove at least the most noticeable outliers.

285 As explained in Sect. 4.6, the covariance structures change considerably (even without outliers) and their changes are tightly associated with the changes in variances. Thus if a procedure deals with principal components calculated from the climate 
Hydrol. Earth Syst. Sci. Discuss., https://doi.org/10.5194/hess-2018-7

Manuscript under review for journal Hydrol. Earth Syst. Sci.

Discussion started: 19 February 2018

(c) Author(s) 2018. CC BY 4.0 License.
Hydrology and

Earth System

Sciences

Discussions

(c) (1)

model outputs (as in Hnilica et al., 2017), it should be based rather on correlation matrix, as the correlation structures are more stable in time and their changes can be further reduced by detecting outliers.

The results from Sect. 4.6 can be evaluated also in a different way. While the correlation is a scale-invariant index, the covariance is affected by a linear transformation. The high changes of covariance and the stability of correlations (relative to covariance) imply that the simulated precipitation time series for the future period can be to a large extent substituted by a linear transformation of the simulated data from the control period. From this point of view a reasonable scenario of future precipitation can be obtained by the corresponding linear transformation of observations, i.e. by the multiplicative delta method (Déqué, 2007).

\section{Summary}

Biases and temporal changes of the cross- and auto-correlation structures in climate projections of daily precipitation were investigated. The simulations of two RCMs driven by three different GCMs were analysed. Biases vary in a range approximately from -0.2 to 0.15 and they are related to regional model (while the CCLM-4-8-17 mostly overestimates correlations, RCA4 underestimates them).

The changes of individual cross-correlation coefficients and the lag-1 auto-correlation were calculated. The results showed that the changes vary in a range approximately from -0.08 to 0.08 , the changes of individual models differ considerably. While in the case of cross-correlations the maximal change is $12 \%$ of the values from the control period, for autocorrelations it reaches almost $30 \%$.

The significance of changes was tested using a bootstrap approach. It was shown that the changes were in many cases caused by the outliers that can strongly affect both cross- and auto-dependence structures. The concept of dependence outliers was presented as the values deviating from the correlation structure. Several examples of the effect of outliers were presented and possible consequences for climate studies were discussed. The exploratory procedure was proposed to detect the dependence outliers in multi-variate data and to quantify their impact on the correlation structures.

Data and code availability. The RCM-derived data, the source code and the plot data are available online at http://doi.org/10.5281/zenodo.1137769, allowing to generate the majority of results (except the results from Sect. 4.1) and to reproduce all plots. The observed data used in Sect. 4.1 are property of the Czech Hydrometeorological Institute and cannot be published due to licence.

Author contributions. JH an MH designed the study and wrote the paper. JH wrote the source codes. VP provided theoretical background for the principal component analysis and for the bootstrap. All authors participated in the interpretation of the results. 
Hydrol. Earth Syst. Sci. Discuss., https://doi.org/10.5194/hess-2018-7

Manuscript under review for journal Hydrol. Earth Syst. Sci.

Discussion started: 19 February 2018

(c) Author(s) 2018. CC BY 4.0 License.

(c) (i)
Hydrology and

Earth System

Sciences

Discussions

Competing interests. The authors declare that they have no conflict of interest.

Acknowledgement. This study was supported by the Czech Science Foundation (grants no. 16-05665S [JH] and 16-16549S $[\mathrm{MH}])$. We acknowledge the World Climate Research Programme's Working Group on Regional Climate, and the Working Group on Coupled Modelling, former coordinating body of CORDEX and responsible panel for CMIP5. We also thank to the climate modelling groups of CLM Community and Rossby Centre (Swedish Meteorological and Hydrological Institute) for producing and making available their model outputs.

\section{References}

Bader, D. C., Covey, C., Gutowski, W. J., Held, I. M., Kunkel, K. E., Miller, R. L., Tokmakian, R. T. and Zhang, M. H.: Climate Models: An Assessment of Strengths and Limitations, US Department of Energy Publications, USA, 2008.

Bárdossy, A. and Pegram, G.: Multiscale spatial recorrelation of RCM precipitation to produce unbiased climate change scenarios over large areas and small, Water Resour. Res., 48, W09502, doi:10.1029/2011WR011524, 2012.

Chen. J., Brissette. F. P. and Lucas-Picher, P.: Assessing the limits of bias-correcting climate model outputs for climate change impact studies, J. Geophys. Res.-Atmos, 120, 1123-1136, doi:10.1002/2014JD022635, 2015.

Davidson, A. C. and Hinkley, D. V.: Bootstrap methods and their application, Cambridge University Press, Cambridge, United Kingdom, 1997.

Déqué, M.: Frequency of precipitation and temperature extremes over France in an anthropogenic scenario: Model results and statistical correction according to observed values, Global Planet. Change, 57, 16-26, doi:10.1016/j.gloplacha.2006.11.030, 2007.

Efstratiadis, A., Dialynas, Y. G., Kozanis, S. and Koutsoyiannis, D.: A multivariate stochastic model for the generation of synthetic time series at multiple time scales reproducing long-term persistence, Environ. Modell. Softw., 62, 139-152, doi:10.1016/j.envsoft.2014.08.017, 2014.

Ehret, U., Zehe, E., Wulfmeyer, V., Warrach-Sagi, K. and Liebert, J.: Should we apply bias correction to global and regional climate model data?, Hydrol. Earth Syst. Sc., 16, 3391-3404, doi:10.5194/hess-16-3391-2012, 2012.

Giorgi, F., Jones, C. and Ghassem, R.: Addressing climate information needs at the regional level: the CORDEX framework, World Meteorological Organization (WMO) Bulletin, 58, 175-183, 2009.

Hanel, M., Kožín, R., Heřmanovský, M. and Roub, R.: An R package for assessment of statistical downscaling methods for hydrological climate change impact studies, Environ. Modell. Softw., 95, 22-28, 2017. 
Hydrol. Earth Syst. Sci. Discuss., https://doi.org/10.5194/hess-2018-7

Manuscript under review for journal Hydrol. Earth Syst. Sci.

Discussion started: 19 February 2018

(c) Author(s) 2018. CC BY 4.0 License.
Hydrology and

Earth System

Sciences

Discussions

Hnilica, J., Hanel, M. and Puš, V.: Multisite bias correction of precipitation data from regional climate models, Int. J. Climatol., 37, 2934-2946, doi:10.1002/joc.4890, 2017.

345 Hoffmann, H. and Rath, T.: Meteorologically consistent bias correction of climate time series for agricultural models, Theor. Appl. Climatol., 110, 129-141, doi:10.1007/s00704-012-0618-x, 2012.

Johnson, F. and Sharma A.: A nesting model for bias correction of variability at multiple time scales in general circulation model precipitation simulations, Water Resour. Res., 48, W01504, doi:10.1029/2011WR010464, 2012.

Mao, G., Vogl, S., Laux, P., Wagner, S. and Kunstmann, H.: Stochastic bias correction of dynamically downscaled precipitation fields for Germany through copula-based integration of gridded observation data, Hydrol. Earth Syst. Sc., 19, 1787-1806, doi:10.5194/hess-19-1787-2015, 2015.

Maraun, D., Wetterhall, F., Ireson, A. M., Chandler, R. E., Kendon, E. J.,Widmann, M., Brienen, S., Rust, H. W., Sauter, T., Themeß1, M., Venema, V. K. C., Chun, K. P., Goodess, C. M., Jones, R. G., Onof, C., Vrac, M. and Thiele-Eich, I.: Precipitation downscaling under climate change: recent developments to bridge the gap between dynamical models and the end user, Rev. Geophys., 48, RG3003, doi:10.1029/2009RG000314, 2010.

Mehrotra, R. and Sharma, A.: Correcting for systematic biases in multiple raw GCM variables across a range of timescales, J. Hydrol., 520, 214-223, doi:10.1016/j.jhydrol.2014.11.037, 2015.

Mehrotra, R. and Sharma, A.: A multivariate quantile-matching bias correction approach with auto-and cross-dependence across multiple time scales: Implications for downscaling. J. Climate, 29, 3519-3539, doi:10.1175/JCLI-D-15-0356.1, 2016.

Piani, C. and Haerter, J. O.: Two dimensional bias correction of temperature and precipitation copulas in climate models, Geophys. Res. Lett., 39, L20401, doi:10.1029/2012GL053839, 2012.

Solomon, S., Qin, D., Manning, M., Chen, Z., Marquis, M., Averyt, K. B., Tignor, M. and Miller, H. L. (Eds): Climate Change 2007: The Physical Science Basis Contribution of Working Group I to the Fourth Assessment Report of the Intergovernmental Panel on Climate Change, Cambridge University Press, Cambridge, United Kingdom and New York, NY, USA, 2007.

Štěpánek, P., Zahradníček, P. and Huth, R.: Interpolation techniques used for data quality control and calculation of technical series: an example of a Central European daily time series, Idojaras, 115, 87-98, 2011.

Teng, J., Potter, N. J., Chiew, F. H. S., Zhang, L., Wang, B., Vaze, J. and Evans, J. P.: How does bias correction of regional climate model precipitation affect modelled runoff?, Hydrol. Earth Syst. Sc., 19, 711-728, doi:10.5194/hess-19-711-2015, 
Hydrol. Earth Syst. Sci. Discuss., https://doi.org/10.5194/hess-2018-7

Manuscript under review for journal Hydrol. Earth Syst. Sci.

Discussion started: 19 February 2018

(c) Author(s) 2018. CC BY 4.0 License.

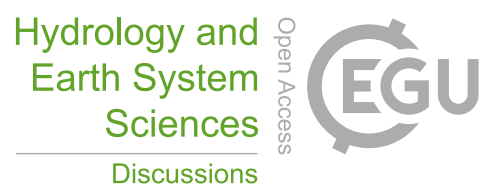

(c) (i)

Teutschbein, C. and Seibert, J.: Bias correction of regional climatemodel simulations for hydrological climate-change impact studies: Review and evaluation of different methods, J. Hydrol., 456, 12-29, doi:10.1016/j.jhydrol.2012.05.052, 2012.

Wilks, D. S.: Statistical methods in the atmospheric science, $3^{\text {rd }}$ edn. Academic, Amsterdam, 2011. 